\title{
Análise de trilha do rendimento de grãos de feijoeiro (Phaseolus vulgaris L.) e seus componentes ${ }^{1}$
}

\author{
Path analysis of grain yield of common bean (Phaseolus vulgaris L.) and its \\ components
}

\author{
Pablo Diego Silva Cabral ${ }^{2 *}$, Taís Cristina Bastos Soares ${ }^{3}$, Andreia Barcelos Passos Lima ${ }^{4}$, Yaska Janaína Bastos \\ Soares $^{5}$ e Josimar Aleixo da Silva
}

\begin{abstract}
Resumo - Cinqüenta e oito genótipos de feijoeiro (Phaseolus vulgaris L.), sendo 32 genótipos locais, 20 genótipos provenientes da EMBRAPA e seis cultivares comerciais, foram avaliados em Alegre/ES, através da influência de oito caracteres de importância agronômica sobre a produção de grãos por unidade de área. O experimento, em blocos casualizados com três repetições, foi conduzido no período das "águas" no ano agrícola de 2008/09. O objetivo deste trabalho foi estimar os coeficientes de trilha entre os caracteres primários e secundários sobre a produtividade de grãos. Os caracteres primários foram constituídos pelo número de sementes por vagem (NSV), peso de cem grãos (P100), número de vagem por planta (NVP) e número de sementes por planta (NSP), os caracteres secundários foram: número de dias da germinação até à floração (FL), número de dias entre a emergência e a maturação de colheita (MC), estatura da planta (EP) e altura da inserção da primeira vagem (PIV). A análise do coeficiente de trilha demonstrou que o caráter primário com maior efeito direto sobre produtividade (PROD) foi NVP $(1,0011)$, associado à alta correlação $(0,754)$. As variáveis P100 e NSV apresentaram altos efeitos indiretos sobre NVP de 0,8848 e 0,6369 , respectivamente. Observou-se um incremento em P100 e NVP em plantas de ciclo e período vegetativo curtos e uma maior altura de inserção da primeira vagem, sendo que o ponto de inserção da primeira vagem não influenciou significativamente a produtividade.
\end{abstract}

Palavras-chave - Feijão. Plantas-melhoramento genético. Culturas agrícolas-rendimento.

\begin{abstract}
Fifty-eight genotypes of common bean (Phaseolus vulgaris L.), being 32 local genotypes, 20 genotypes from EMBRAPA and six commercial cultivars were evaluated in Alegre/ES, through the influence of eight characters of agronomic importance to grain production by unit area. The experiment was conducted in a randomized block design with three replications in the wet period of 2008/09 crop year. This study aimed to estimate the path coefficients between the primary and secondary characters on grain yield. The primary characters were set up by the number of seeds per pod (NSV), weight of one hundred grains (P100), number of pods per plant (NVP) and number of seeds per plant (NSP) and the secondary traits were number of days from germination to flowering (FL), number of days between emergence and harvest maturity (MC), plant height (EP), height of the first pod (PIV). The analysis of the path coefficient showed that the primary character with more direct effect on yield (PROD) was NVP (1.0011), associated with high correlation (0.754). Variables P100 and NSV showed high indirect effect on NVP of 0.8848 and 0.6369 , respectively. It was observed an increase in P100 and NVP in plants with short cycle and growing season and first pod height taller, and that the height of the first pod did not significantly influence productivity.
\end{abstract}

Key words - Beans. Plant breeding. Crop yield.

\footnotetext{
* Autor para correspondência

${ }^{1}$ Recebido para publicação em 03/05/2010; aprovado em 30/12/2010

Parte da dissertação de Mestrado do primeiro autor, apresentada ao Programa de Pós-Graduação em Produção Vegetal, CCA/UFES

${ }^{2}$ Bolsista da UENF/FAPERJ, Programa de Pós-Graduação em Genética e Melhoramento de Plantas, UENF, Campos dos Goytacazes- RJ, Brasil, 28013-602, pablodscabral@hotmail.com

${ }^{3}$ Departamento de Zootecnia, CCA/UFES, alto universitário, Campus Universitário, s/n, Alegre- ES, Brasil, 29500-000, tcbsoares@yahoo.com.br ${ }^{4}$ Departamento de Produção Vegetal, CCA/UFES, alto universitário, Campus Universitário, s/n, Alegre- ES, Brasil, 29500-000, andreiabpl@yahoo.com.br ${ }_{5}^{5}$ Bolsista da UENF/FAPERJ, Programa de Pós-Graduação em Produção Vegetal, UENF, Campos dos Goytacazes- RJ, Brasil, 28013-602, yaskasoares@ yahoo.com.br

${ }^{6}$ Bolsista de extensão/UFES, graduando do Curso de Agronomia do CCA-UFES, alto universitário, Campus Universitário, s/n, Alegre- ES, Brasil, 29500-000,josimaraleixo_@hotmail.com
} 


\section{Introdução}

O cultivo de feijoeiro é de grande importância no contexto sócio-econômico nacional. Segundo Bonett et al., (2006) o feijão é um dos mais importantes constituintes da dieta do brasileiro, principalmente, por ser uma excelente fonte protéica. O feijoeiro é cultivado, praticamente em todo território nacional com um rendimento médio de $904 \mathrm{~kg} \mathrm{ha}^{-1}$ (CONAB, 2010), sendo o Brasil destaque no cenário internacional como o maior produtor e consumidor de feijão. Esta produtividade média é considerada baixa, principalmente pelo fato do pequeno uso de sementes certificadas e pelo manejo inadequado da cultura.

Atualmente, os programas de melhoramento de feijoeiro no Brasil têm visado a expressão do potencial produtivo econômico, e componentes relacionados, por meio de técnicas de melhoramento apropriadas. $\mathrm{O}$ fato de que a maioria dos pequenos agricultores não adquirirem sementes comerciais para o plantio, reutilizando as suas próprias sementes, ou as sementes do vizinho, pode propiciar a mistura mecânica e a ocorrência de cruzamentos naturais entre os indivíduos que são semeados anualmente (BONETT et al., 2006). Fato esse que gera uma ampla variabilidade genética em poder dos pequenos agricultores, e que poderia ser usado pelos programas de melhoramento uma vez que, segundo Cabral et al. (2010), Silva et al. (2008) e Vieira et al. (2008), a variabilidade genética é essencial para o sucesso de programas de melhoramento de praticamente todos os caracteres de importância econômica. Com a utilização das técnicas de melhoramento genético do feijoeiro, podem-se alcançar informações concretas de adaptabilidade e produtividade nas diversas regiões com possível potencial produtivo. Considerando a análise de trilha para rendimento e componentes relacionados, diretos e indiretos, Hoogerheide et al. (2007) relataram que o conhecimento do grau dessa associação, por meio de estudos de correlações, possibilita identificar caracteres que possam ser usados como critérios de seleção indireta para a produtividade em programas de melhoramento.

Para que a avaliação da associação entre caracteres tenha uma estimativa e gere uma interpretação biologicamente apropriada e segura, é de fundamental importância que se teste o grau de colinearidade entre as variáveis independentes (COIMBRA et al., 2005). A multicolinearidade está associada com as interrelações entre as variáveis previamente estudadas independentes e, nesse contexto, Kurek et al. (2001) comentaram que a análise de trilha ou "Path analysis" é um artifício que o melhorista dispõe para entender as causas envolvidas nas associações entre caracteres e decompor a correlação existente em efeitos diretos e indiretos, por intermédio de uma variável principal, como o rendimento de grãos em feijoeiro, e as variáveis explicativas, ou seja, os componentes primários e secundários do rendimento de grãos.

A análise de trilha vem sendo utilizada por vários autores em diversas culturas de importância econômica como algodão (HOOGERHEIDE et al., 2007), trigo (VIEIRA et al., 2007), feijão (COIMBRA et al., 1999; FURTADO et al., 2002 ; KUREK et al., 2001;), capimelefante (DAHER et al., 2004), espécies florestais exóticas (LORENTZ et al., 2006), feijão-bravo (SILVA et al., 2009), pimentão (CARVALHO et al., 1999) e canola (COIMBRA et al., 2005). Esta pode ser obtida a partir de correlações fenotípicas, genotípicas, ambientais, dentre outras (CRUZ e CARNEIRO, 2003), sendo a fenotípica a mais utilizada pelos melhoristas.

Sendo assim, o objetivo do presente trabalho foi avaliar por meio da correlação fenotípica, a relação direta e indireta existente entre o rendimento de grãos de feijoeiro com os seus componentes primários e secundários, visando auxiliar o pesquisador no processo de seleção de plantas.

\section{Material e métodos}

O experimento foi conduzido na Área Experimental do Centro de Ciências Agrárias da Universidade Federal do Espírito Santo (CCA-UFES), no ano agrícola de 2008/2009 e constituiu de 58 acessos, sendo 32 genótipos locais pertencentes à comunidade Fortaleza no município de Muqui-ES, 20 genótipos provenientes da EMBRAPA e seis cultivares comerciais: Carioca, Serrano, Pérola, IAPAR 31, IAPAR 44 e IAPAR 81. O delineamento utilizado foi o de blocos casualizados (DBC) com três repetições. A unidade experimental foi composta por cinco filas de $1,2 \mathrm{~m}$ de comprimento, espaçadas $0,5 \mathrm{~m}$, com densidade de semeadura de 10 sementes por metro linear, totalizando uma área de $3,0 \mathrm{~m}^{2}$ por unidade experimental. Foi considerada como bordadura, a primeira e a última fila e a primeira e última planta de cada fila por parcela, sendo avaliadas 20 plantas previamente marcadas ao acaso em cada unidade experimental. O preparo do solo foi realizado convencionalmente, a correção e a adubação realizadas segundo Prezotti et al. (2007) e os tratos culturais feitos manualmente.

Foram avaliados nove caracteres, sendo eles: 1) variável principal - rendimento de grãos em $\mathrm{kg} \mathrm{ha}^{-1}$ (PROD), 2), variáveis explicativas primárias - número de semente por vagem (NSV), peso de cem grãos (P100), número de vagem por planta (NVP), número de semente por planta (NSP) e 3) variáveis explicativas secundárias - número de dias da germinação até que $90 \%$ das plantas 
da parcela estejam em estádio de floração (FL), número de dias em que $90 \%$ das plantas da parcela estejam na maturação de colheita (MC), estatura da planta em $\mathrm{cm}$, no estádio de maturação fisiológica (EP), altura em $\mathrm{cm}$ da inserção da primeira vagem, no estádio de maturação fisiológica (PIV), conforme Bonett et al. (2006) e Coelho et al. (2007), e posteriormente analisado o coeficiente de trilha, conforme visualizado na Figura 1.

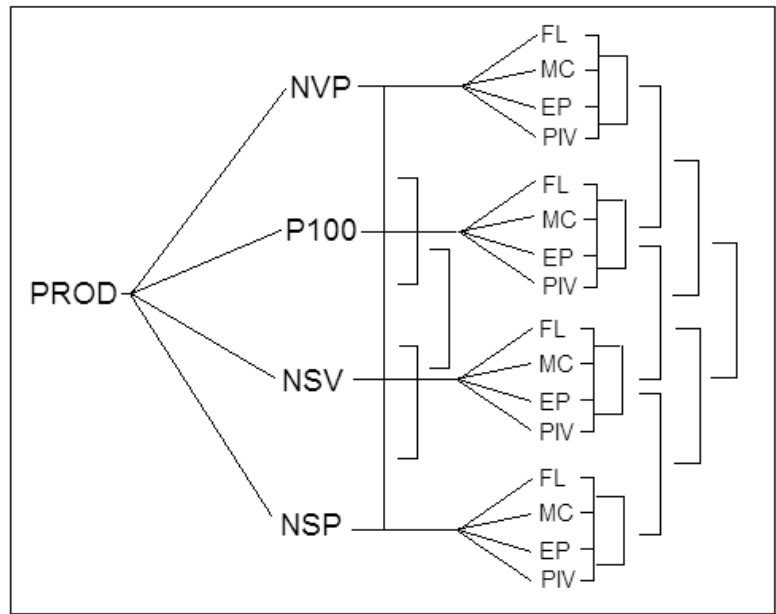

Figura 1 - Diagrama causal em cadeia, demonstrando o relacionamento dos componentes secundários $(\mathrm{FL}=$ número de dias para a floração; $\mathrm{MC}=$ número de dias para a maturação de colheita; $\mathrm{EP}=$ estatura de planta em $\mathrm{cm} ; \mathrm{PIV}=$ ponto de inserção da primeira vagem) sobre os componentes primários (NVP = número de vagem por planta; $\mathrm{P} 100=$ peso de cem sementes; NSV = número de sementes por vagem; NSP = número de sementes plantas) e desses sobre a variável rendimento de grãos (PROD)
Para as análises estatísticas, primeiramente foi realizado o diagnóstico de multicolinearidade, em seguida, a análise de trilha conforme descrita por CRUZ e CARNEIRO (2003). Utilizou-se o Software GENES (CRUZ, 2006).

\section{Resultados e discussão}

$\mathrm{Na}$ análise de multicolinearidade foi verificado o grau de severidade próximo a fraca, segundo os critérios propostos por Montgomery e Peck citados por Cruz e Carneiro (2003). Carvalho (1995) ressalta a importância desse estudo quando se tem objetivo de realizar análises de regressões, de trilha, de índice de seleção, entre outras. Cruz e Carneiro (2003) relatam que as estimativas dos parâmetros sob multicolinearidade, podem assumir valores absurdos ou sem nenhuma coerência com os fenômenos biológicos estudados.

As estimativas de correlação fenotípica $\left(r_{p}\right)$ avaliadas para as nove características agronômicas estão apresentadas na Tabela 1, sendo que estas variaram entre 0,0079 a 0,8839. De acordo com Coimbra et al. (1999), as correlações são, em geral, explicadas pelo efeito aditivo dos genes, afetando dois caracteres simultaneamente, demonstrando assim a importância do conhecimento do grau de associação entre caracteres agronômicos, principalmente porque a seleção sobre determinado caráter pode alterar o comportamento do outro.

Pode-se observar que os caracteres NSP e NVP estão altamente correlacionados com a variável principal PROD (TAB. 1). Assim, segundo Kurek et al. (2001) os caracteres com baixa herdabilidade tendem a dificultar

Tabela 1 - Coeficiente de correlação fenotípica $\left(\mathrm{r}_{\mathrm{p}}\right)$ entre os caracteres ${ }^{1} \mathrm{PROD}, \mathrm{NSV}, \mathrm{NVP}, \mathrm{NSP}, \mathrm{P} 100$, EP, PIV, FL e MC em 58 genótipos de feijão. Alegre/ES 2008/09

\begin{tabular}{|c|c|c|c|c|c|c|c|c|c|}
\hline Variáveis & PROD & NSV & NVP & NSP & P100 & EP & PIV & FL & $\mathrm{MC}$ \\
\hline PROD & 1 & 0,474 & 0,754 & 0,835 & 0,1637 & $-0,089$ & $-0,09$ & $-0,520$ & $-0,381$ \\
\hline NSV & & 1 & 0,220 & 0,636 & $-0,378$ & 0,021 & $-0,231$ & 0,052 & 0,201 \\
\hline NVP & & & 1 & 0,883 & $-0,276$ & 0,129 & 0,007 & $-0,287$ & $-0,204$ \\
\hline NSP & & & & 1 & $-0,371$ & 0,111 & $-0,082$ & $-0,231$ & $-0,085$ \\
\hline P100 & & & & & 1 & $-0,340$ & 0,052 & $-0,512$ & $-0,551$ \\
\hline EP & & & & & & 1 & 0,390 & 0,106 & 0,315 \\
\hline PIV & & & & & & & 1 & $-0,252$ & $-0,122$ \\
\hline $\mathrm{FL}$ & & & & & & & & 1 & 0,735 \\
\hline $\mathrm{MC}$ & & & & & & & & & 1 \\
\hline
\end{tabular}

${ }^{1} \mathrm{PROD}=$ rendimento de grãos, NSV = número de sementes por vagem, NVP = número de vagem por plantas, NSP = número de semente por planta, $\mathrm{P} 100=$ peso de cem sementes, $\mathrm{EP}=$ estatura de planta, $\mathrm{PIV}=$ ponto de inserção da primeira vagem, $\mathrm{FL}=$ número de dias para a floração e $\mathrm{MC}=$ número de dias para a maturação de colheita 
o processo de seleção, devido à grande influência do ambiente. Por outro lado, se um caráter auxiliar apresentar alta herdabilidade e estiver correlacionado com o caráter de interesse com baixa herdabilidade, é muito mais vantajoso realizar seleção de modo indireto por intermédio do caráter auxiliar.

Observa-se ainda na Tabela 1, uma boa concordância na direção e na magnitude do coeficiente de correlação fenotípica $\left(r_{p}\right)$ para a maioria dos pares de caracteres agronômicos avaliados. Por outro lado, as variáveis secundárias (EP, PIV, FL e MC) estão em geral correlacionadas em magnitude média a pequena e sentido contrário com a variável principal PROD, e também com as variáveis primárias P100 e NSP. Resultados semelhantes foram encontrados por Coimbra et al. (1999), Collicchio et al. (1997) e por Lana et al. (2003), sendo que esses últimos afirmaram não existir associação entre os caracteres estatura da planta, produtividade de grãos e peso médio de mil grãos.

Considerando o $r_{p}$ apresentado na Tabela 1, observase que o maior potencial de rendimento de grãos está associado ao aumento do número de sementes por planta, do número de vagem por planta e do número de sementes por vagem, juntamente com o menor ciclo vegetativo e reprodutivo da planta, concordando com os resultados obtidos por Coimbra et al. (1999).

O estudo de correlações é uma medida de associação e não permite concluir sobre o estudo da relação de causa e efeito. Por isso, procedeu-se à análise de trilha, que investiga a relação de causa e efeito. Silva et al. (2005) mencionam que esta análise proporciona um conhecimento detalhado das influências dos caracteres envolvidos, e justificam a existência de correlações positivas e negativas, de alta e baixa magnitude, entre os caracteres estudados.

Os caracteres genotípicos que não são fenotipicamente correlacionados podem não ter valor prático na seleção, porque a seleção é, geralmente, realizada com base no fenótipo (SHUKLA et al., 1998 citado por HOOGERHEIDE et al., 2007). Por isso, preferiu-se utilizar a correlação fenotípica para a análise de trilha, por ser esta a que o melhorista manipula.

Assim, na Tabela 2, são apresentados os efeitos diretos e indiretos das variáveis explicativas primárias sobre o rendimento de grãos, com base no esquema casual mostrado na Figura 1. O coeficiente de determinação $\left(R^{2}\right)$ equivalente a $95,9 \%$ e o efeito residual $(0,2024)$ obtidos, indicam que as variáveis explicativas determinaram, quase que totalmente, a variação da variável básica (PROD).

Analisando os efeitos diretos dos componentes primários sobre a variável principal (TAB. 2), das quatro variáveis primárias (NSV, P100, NVP e NSP), nota-se que NVP apresentou o maior valor de efeito direto, enquanto as outras variáveis explicativas apresentaram valores mais baixos. Sendo ainda que, NVP apresentou alto valor de correlação com PROD, conforme apresentado na Tabela 1. Demonstrando assim, uma boa combinação entre o coeficiente de trilha e o de correlação fenotípica, indicando grande contribuição desta variável para o aumento do PROD. Resultados semelhantes foram encontrados por Coimbra et al. (1999), Kurek et al. (2001) e Furtado et al. (2002).

Tabela 2 - Estimativas dos efeitos diretos e indiretos dos componentes primários da produção ${ }^{1} \mathrm{NSV}, \mathrm{P} 100$, NVP, NSP, sobre a variável principal ${ }^{2} \mathrm{PROD}$, de 58 genótipos de feijão comum. Alegre/ES, 2008/09

\begin{tabular}{|c|c|c|c|}
\hline \multicolumn{2}{|c|}{ Variável NSV } & \multicolumn{2}{|c|}{ Variável NVP } \\
\hline Efeito direto sobre PROD & 0,045 & Efeito direto sobre PROD & 1,0011 \\
\hline Efeito indireto via P100 & 0,0031 & Efeito indireto via NSV & 0,0286 \\
\hline Efeito indireto via NVP & 0,6369 & Efeito indireto via P100 & 0,0122 \\
\hline Efeito indireto via NSP & $-0,2106$ & Efeito indireto via NSP & $-0,2066$ \\
\hline TOTAL & 0,4743 & TOTAL & 0,8353 \\
\hline \multicolumn{2}{|c|}{ Variável P100 } & \multicolumn{2}{|c|}{ Variável NSP } \\
\hline Efeito direto sobre PROD & 0,0138 & Efeito direto sobre PROD & 0,5563 \\
\hline Efeito indireto via NSV & 0,0099 & Efeito indireto via NSV & $-0,017$ \\
\hline Efeito indireto via NVP & 0,8848 & Efeito indireto via P100 & $-0,0038$ \\
\hline Efeito indireto via NSP & $-0,1537$ & Efeito indireto via NVP & $-0,3718$ \\
\hline TOTAL & 0,7549 & TOTAL & 0,1637 \\
\hline
\end{tabular}

${ }^{1} \mathrm{NSV}=$ número de sementes por vagem, $\mathrm{NVP}=$ número de vagem por plantas, $\mathrm{NSP}=$ número de semente por planta, $\mathrm{P} 100=$ peso de cem sementes, ${ }^{2} \mathrm{PROD}=$ rendimento de grãos 
Os efeitos indiretos foram relativamente altos, sendo que P100 e NSV tiveram um efeito indireto sobre a variável NVP de 0,8848 e 0,6369, respectivamente. Este resultado é um indicativo da viabilidade da seleção indireta para obtenção de ganhos no caráter de maior importância primária.

Analisando o efeito indireto, na Tabela 2, observouse o sentido contrário (negativo) da variável NSP sobre as outras variáveis explicativas, diminuindo assim, não só o efeito direto desta, mas também o efeito total das outras variáveis sobre o PROD. Indicando que o aumento de NSP pode ocasionar diminuição das outras variáveis explicativas, mesmo que essa tenha um efeito direto sobre rendimento de grãos na magnitude de 0,5563. Assim, segundo Coimbra et al. (1999) é de se esperar que a seleção truncada no caráter auxiliar possa não proporcionar ganhos satisfatórios na variável básica (PROD). Nestes casos, a melhor estratégia é a seleção simultânea de caracteres, com ênfase também nos caracteres cujos efeitos indiretos são significativos (CRUZ; CARNEIRO, 2003; SANTOS et al., 1994).

As variáveis primárias que mais contribuíram para o aumento de PROD foram NVP, P100 e NSV, respectivamente, sendo que NVP contribuiu de forma direta e indireta e P100 e NSV tiveram maior contribuição de forma indireta.

Os resultados da análise de trilha dos caracteres secundários, para cada componente primário, estão descritos na Tabela 3. Por meio deles é possível

Tabela 3 - Estimativas de efeitos diretos e indiretos dos componentes secundários ('EP, MC, FL e PIV) sobre os componentes primários ( ${ }^{2} \mathrm{NSV}, \mathrm{P} 100, \mathrm{NVP}$ e NSP) na produção de grãos de feijão comum. Alegre/ES, 2008/09

\begin{tabular}{|c|c|c|c|c|}
\hline \multirow{2}{*}{ Descrição do efeito } & \multicolumn{4}{|c|}{ Componente primário } \\
\hline & NSV & $\mathrm{P} 100$ & NVP & NSP \\
\hline Direto de EP & 0,0452 & 0,2591 & 0,2194 & $-0,246$ \\
\hline Indireto via $\mathrm{MC}$ & $-0,1085$ & $-0,0698$ & $-0,0998$ & 0,0177 \\
\hline Indireto via FL & $-0,0311$ & $-0,031$ & $-0,0423$ & $-0,0302$ \\
\hline Indireto via PIV & 0,1161 & $-0,0292$ & 0,0338 & $-0,0817$ \\
\hline \multirow[t]{2}{*}{ TOTAL } & 0,0217 & 0,1291 & 0,1111 & $-0,3402$ \\
\hline & NSV & $\mathrm{P} 100$ & NVP & NSP \\
\hline Direto de MC & $-0,2775$ & $-0,1785$ & $-0,2553$ & 0,0454 \\
\hline Indireto via EP & 0,0177 & 0,1013 & 0,0857 & $-0,0962$ \\
\hline Indireto via FL & 0,0739 & 0,0738 & 0,1005 & 0,0719 \\
\hline Indireto via PIV & $-0,0451$ & 0,0113 & $-0,0131$ & 0,0317 \\
\hline \multirow[t]{2}{*}{ TOTAL } & $-0,231$ & 0,0079 & $-0,0821$ & 0,0528 \\
\hline & NSV & P100 & NVP & NSP \\
\hline Direto de FL & $-0,293$ & $-0,2924$ & $-0,3983$ & $-0,2847$ \\
\hline Indireto via EP & 0,0048 & 0,0275 & 0,0233 & $-0,0261$ \\
\hline Indireto via $\mathrm{MC}$ & 0,07 & 0,0451 & 0,0644 & $-0,0114$ \\
\hline Indireto via PIV & 0,2708 & $-0,068$ & 0,0788 & $-0,1906$ \\
\hline \multirow[t]{2}{*}{ TOTAL } & 0,0527 & $-0,2879$ & $-0,2318$ & $-0,5129$ \\
\hline & NSV & P100 & NVP & NSP \\
\hline Direto de PIV & 0,3684 & $-0,0925$ & 0,1072 & $-0,2594$ \\
\hline Indireto via EP & 0,0142 & 0,0816 & 0,0691 & $-0,0775$ \\
\hline Indireto via $\mathrm{MC}$ & 0,0339 & 0,0218 & 0,0312 & $-0,0055$ \\
\hline Indireto via FL & $-0,2153$ & $-0,2149$ & $-0,2928$ & $-0,2093$ \\
\hline \multirow[t]{2}{*}{ TOTAL } & 0,2013 & $-0,204$ & $-0,0852$ & $-0,5517$ \\
\hline & NSV & P100 & NVP & NSP \\
\hline${ }^{3} \mathrm{R}^{2}$ & 0,1238 & 0,1351 & 0,1285 & 0,3752 \\
\hline${ }^{4} \mathrm{EVR}$ & 0,936 & 0,93 & 0,9335 & 0,7904 \\
\hline
\end{tabular}

$\mathrm{EP}=$ estatura de planta em $\mathrm{cm}, \mathrm{MC}=$ número de dias para a maturação de colheita, $\mathrm{FL}=$ número de dias para a floração, $\mathrm{PIV}=$ ponto de inserção da primeira vagem. ${ }^{2} \mathrm{NSV}=$ número de sementes por vagem, NVP $=$ número de vagem por plantas, NSP $=$ número de semente por planta, $\mathrm{P} 100=$ peso de cem sementes. ${ }^{3} \mathrm{R}^{2}=$ Coeficiente de determinação; ${ }^{4} \mathrm{EVR}=$ efeito da variável residual 
identificar caracteres que podem maximizar as respostas correlacionadas num programa de melhoramento genético da cultura. Pode-se observar que os efeitos diretos das variáveis secundárias sobre as primárias podem ser considerados de magnitude relativamente baixa.

A variável secundária FL apresentou sentido contrário para todas as variáveis primárias (TAB. 3). Assim, a seleção indireta desta variável poderá implicar na redução das variáveis primárias, influenciando negativamente a seleção para PROD, já que todas as variáveis primárias têm sentidos positivo sobre o rendimento. Esse sentido negativo foi observado também com MC sobre NSV, P100 e NVP e também de PIV sobre P100 e NSP.

Os efeitos diretos de EP sobre P100 e NVP e de PIV em NSV, demonstrados na Tabela 3, são de sentido positivo e magnitude considerada significativa, indicando que a seleção indireta dessas duas variáveis (EP e PIV) pode ser viável. Assim, para aumentar NVP, sendo esta a variável de maior contribuição para o aumento de PROD, devem ser considerados ciclo e período vegetativo curtos e maior estatura da planta, sendo que o ponto de inserção da primeira vagem não influenciou significativamente o aumento de NVP, pois, na maioria das vezes, não supera a estimativa do efeito residual..

Nesse estudo não foram encontrados caracteres secundários morfológicos de grande importância na determinação do rendimento de grãos e de seus caracteres primários. Vieira et al. (2007), trabalhando com análise de trilha do rendimento de grãos em trigo, com variáveis primárias e secundárias, não encontraram caracteres secundários de importância na determinação de caracteres primários.

Devido aos baixos coeficientes de determinação e aos altos valores residuais em todas as análises de trilha dos componentes secundários sobre os primários, essas observações devem ser cuidadosamente avaliadas em ensaios posteriores. Contudo, os resultados obtidos para os componentes primários e secundários são concordantes com os apresentados por Coimbra et al.(1999), Furtado et al. (2002), Kurek et al. (2001) e Santos et al. (1994).

\section{Conclusões}

1. Entre os componentes primários do rendimento de grãos, o número de vagem por planta, o peso de cem sementes e o número de sementes por vagem são os caracteres de maiores potencialidades para seleção e identificação de genótipos superiores para rendimento de grãos em feijoeiro;

2. O caráter número de semente por planta demonstrou correlação negativa com número de vagem por planta, portanto a seleção de plantas com maior número de grãos implicará na redução do número de vagem por planta.

\section{Agradecimentos}

Os autores agradecem à Fundação de Amparo à Pesquisa do Espírito Santo (FAPES) e à Coordenação de Aperfeiçoamento de Pessoal de Nível Superior (CAPES), pelo financiamento do projeto e pela concessão da bolsa de mestrado ao primeiro autor, respectivamente.

\section{Referências}

BONETT, L. P. et al. Divergência genética em germoplasma de feijoeiro comum coletado no estado do Paraná, Brasil. Semina: Ciências Agrárias, v. 27, n. 04, p. 547-560, 2006.

CABRAL, P. D. S. et al. Quantification of the diversity among common bean accessions using Ward-MLM strategy. Pesquisa Agropecuária Brasileira, v. 45, n.10, p. 1124-1132, 2010.

CARVALHO, C. G. P. et al. Análise de trilha sob multicolinearidade em pimentão. Pesquisa Agropecuária Brasileira, v.3 4, n. 04, p. 603-613, 1999.

CARVALHO, S. P. Métodos alternativos de estimação do coeficiente de trilha $e$ índices de seleção, sob multicolinearidade. 1995. 163 f. Tese (Doutorado em Genética e Melhoramento) - Universidade Federal de Viçosa, Viçosa.

COELHO, C.M.M.; COIMBRA, J.L.M.; SOUZA, C.A. de.; BOGO, A.; GUIDOLIN, A.F.Diversidade genética em acessos de feijão (Phaseolus vulgaris L.). Ciência Rural, v. 37, n. 05, p. 1241-1247, 2007.

COIMBRA, J. L. M. et al. Análise de Trilha I: Análise do Rendimento de Grãos e seus Componentes. Ciência Rural, v. 29, n. 02, p. 213-218, 1999.

COIMBRA, J. L. M. et al. Conseqüências da multicolinearidade sobre a análise de trilha em canola. Ciência Rural, v. 35, n. 02, p. 347-352, 2005.

COllicChio, E., RAmalho, M. A. P., ABREU, A. F. Associação entre porte da planta do feijoeiro e o tamanho de grãos. Pesquisa Agropecuária Brasileira, v. 32, n. 03, p. 297-304, 1997.

CONAB - Companhia Nacional de Abastecimento. Acompanhamento da safra brasileira de grãos 2009/2010. 2010. Disponível em: http://www.conab.gov.br/conabweb. Acesso em: 21 de abriu de 2010.

CRUZ, C. D. Programa GENES: Biometria. Editora UFV. Viçosa, MG, 2006. 382 p.

CRUZ, C. D.; CARNEIRO, P. C. S. Modelos Biométricos aplicados ao Melhoramento Genético. Viçosa: UFV, v.2, 2003. $585 \mathrm{p}$. 
DAHER, R. F. et al. Análise de trilha de caracteres forrageiros do capim-elefante (Pennisetum purpureum Schum.). Ciência Rural, v. 34, n. 05, p.1531-1535, 2004.

FURTADO, M. R. et al. Análise de Trilha do Rendimento do Feijoeiro e Seus Componentes Primários em Monocultivo e em Consórcio com a Cultura do Milho. Ciência Rural, v. 32, n. 02, p. 217-220, 2002.

HOOGERHEIDE, E. S. S. et al. Correlações e análise de trilha de caracteres tecnológicos e a produtividade de fibra de algodão. Pesquisa Agropecuária Brasileira, v. 42, n. 10, p. 1401-1405, 2007.

KUREK, A. J. et al. Análise de Trilha como Critério de Seleção Indireta para Rendimento de Grãos em Feijão. Revista Brasileira de Agrociência, v. 07, n. 01, p. 29-32, 2001.

LANA, A. M. Q.; CARDOSO, A. A.; CRUZ, C. D. Herdabilidades e correlações entre caracteres de linhagens de feijão obtidas em monocultivo e em consórcio com o milho. Ciência Rural, v. 33, n. 06 , p. 1031-1037, 2003.

LORENTZ, L. H.; FORTES, F. O.; LÚCIO, A. D. Trilha entre as variáveis das análises de sementes de espécies florestais exóticas do Rio Grande do Sul. Revista Árvore, v. 30, n. 04, p. $567-574,2006$.
PREZOTTI, L. C. et al. Manual de Recomendação de Calagem e Adubação para o estado do Espírito Santo - $5^{\text {a }}$ aproximação. SEEA/INCAPER/CREDAGRO, Vitória, ES, 2007. 305p.

SANTOS, C. A. F. et al. Correlações canônicas entre componentes primários e secundários da produção de grãos em guandu (Cajanus cajan (L.) Millsp.). Revista Ceres, v. 41, n. 236, p. 459-464, 1994.

SILVA, G.O. da; et al. Importância de caracteres na dissimilaridade de progênies de batata em gerações iniciais de seleção. Bragantia, v. 67, n. 01, p. 141-144, 2008.

SILVA, M. A. et al. Análise de trilha para caracteres morfológicos do feijão-bravo (Capparis flexuosa) no cariri paraibano. Archivos de zootecnia, v. 58, n. 221, p. 121-124, 2009.

SILVA, S. A. et al. Análise de trilha para os componentes de rendimento de grãos em trigo. Bragantia, v. 64, p. 191-196, 2005.

VIEIRA, E. A. et al. Divergência genética entre acessos açucarados e não açucarados de mandioca. Pesquisa Agropecuária Brasileira, v. 43, n. 12, p. 1707-1715, 2008.

VIEIRA, E. A. et al. Análise de Trilha entre os componentes primários e secundários do rendimento de grãos em trigo. Revista Brasileira de Agrociência, v. 13, n. 02, p. 169 -174, 2007. 